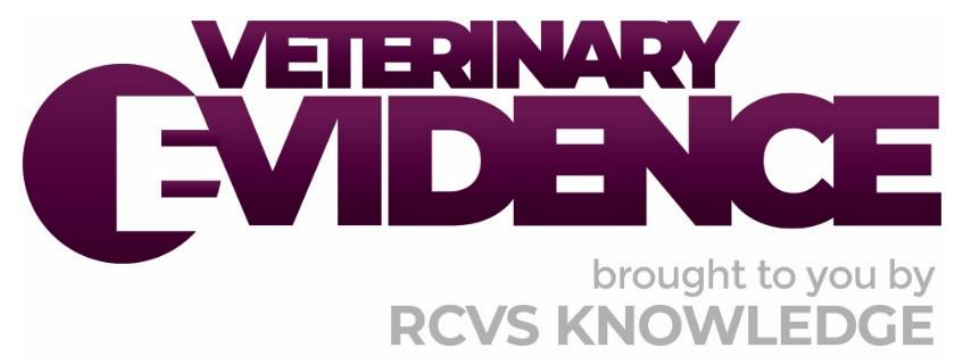

\title{
Mortality rate comparison of enterotomy and resection and anastomosis (enterectomy) in dogs with foreign-body obstructions
}

\author{
A Knowledge Summary by
}

Hillary Mikulak DVM ${ }^{1^{*}}$

Wanda J. Gordon-Evans DVM DACVS-SA ${ }^{1}$

\footnotetext{
${ }^{1}$ BluePearl Veterinary Hospital, 7717 Flying Cloud Drive, Eden Prairie, MN 55344, USA

${ }^{2}$ University of Minnesota College of Veterinary Medicine, 1365 Gortner Ave, St Paul, MN 55108, USA

*Corresponding Author (mikul073@umn.edu)
}

ISSN: 2396-9776

Published: 30 Dec 2021

in: The Veterinary Evidence journal Vol 6, Issue 4

DOI: https://doi.org/10.18849/ve.v6i4.390

Reviewed by: Zofia Lisowski (BVSc PhD AFHEA MRCVS) and

Faye Swinbourne (BVM\&S MVetMed DiplECVS

Next Review Date: 25 Oct 2022 


\section{KNOWLEDGE SUMMARY}

\section{PICO question}

In dogs with gastrointestinal foreign-body obstruction undergoing surgical correction, is the mortality rate in the perioperative period for those receiving resection and anastomosis higher, lower, or equivalent to those receiving an enterotomy?

\section{Clinical bottom line}

\section{Category of research question}

\section{Outcome}

The number and type of study designs reviewed

Four retrospective studies were reviewed

\section{Strength of evidence}

Weak

\section{Outcomes reported}

It would appear that the mortality rate for resection and anastomosis for the purpose of foreign-body removal is higher than that of enterotomies performed for the same reason

\section{Conclusion}

There is insufficient evidence directly comparing enterotomies with resection and anastomoses in foreignbody obstructions to definitively state that the mortality rate is higher among resection and anastomosis procedures

\section{How to apply this evidence in practice}

The application of evidence into practice should take into account multiple factors, not limited to: individual clinical expertise, patient's circumstances and owners' values, country, location or clinic where you work, the individual case in front of you, the availability of therapies and resources.

Knowledge Summaries are a resource to help reinforce or inform decision making. They do not override the responsibility or judgement of the practitioner to do what is best for the animal in their care.

\section{Clinical Scenario}

A foreign-body obstruction is diagnosed in a canine patient. An owner wishes to wait longer to decide to go to surgery risking additional intestinal damage. The owner wants to know if a resection and anastomosis became necessary instead of an enterotomy, would the risk of death increase.

\section{The evidence}

The available evidence is exclusively retrospective clinical studies. Therefore, they suffer from inherent retrospective bias. There are no studies that aim to specifically compare mortality rates between enterotomies and resection and anastomoses in dogs whose indication for surgery is foreign-body obstruction. Many studies found relevant to the subject of the PICO question do not separate the reported data in a way that maintains 
direct relevance to the PICO question. Therefore, the studies all had small sample sizes relating specifically to mortality rates pertaining to foreign-body obstructions. Studies directly comparing mortality rate between enterotomy and resection and anastomoses procedures for foreign-body removal in dogs would be valuable.

\section{Summary of the evidence}

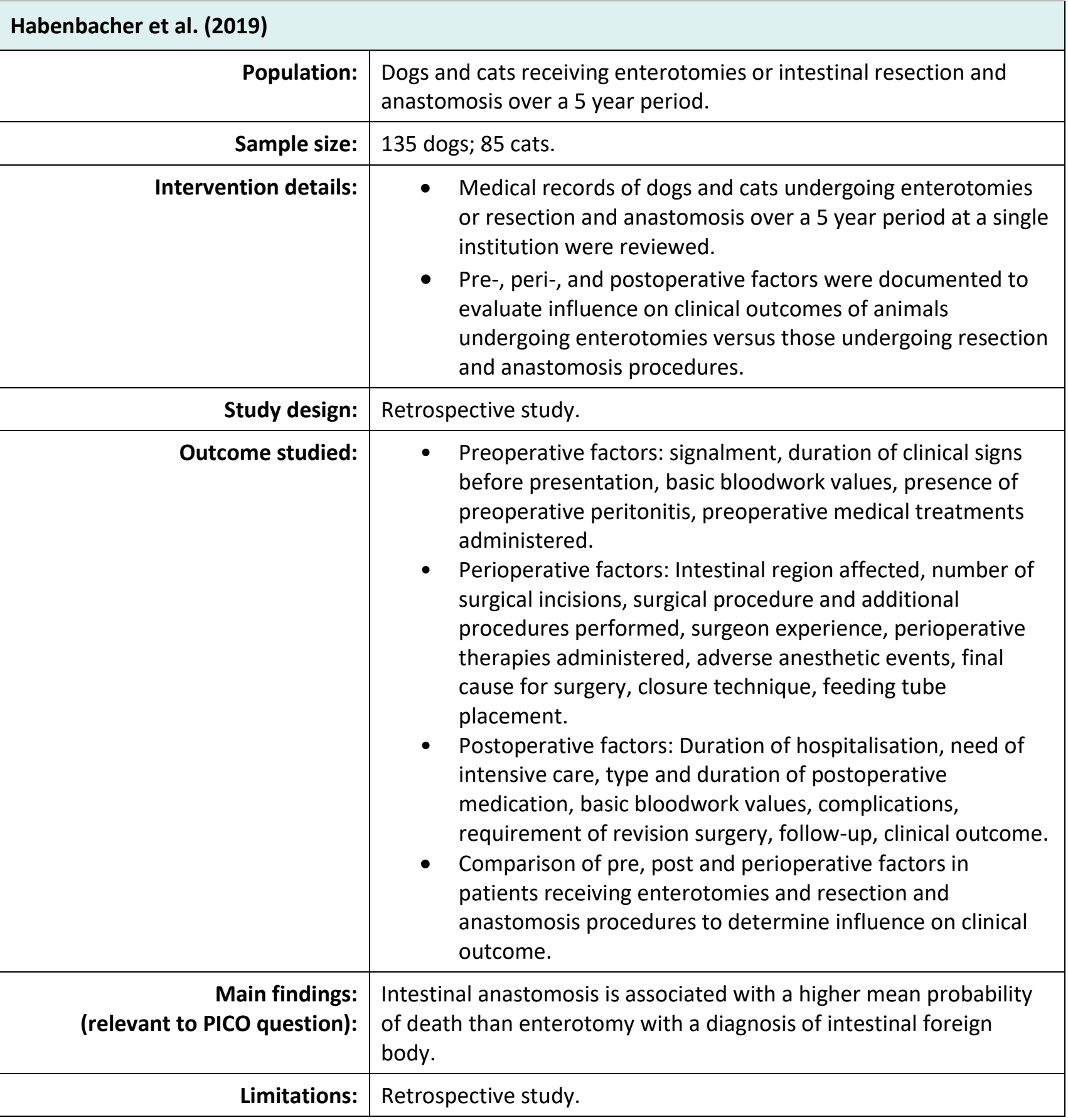

Rosenbaum et al. (2016)

\begin{tabular}{|r|l|}
\hline Population: & $\begin{array}{l}\text { Dogs that underwent intestinal resection and anastomosis using } \\
\text { disposable skin staples from 2000-2014. }\end{array}$ \\
\hline Sample size: & 63 dogs. \\
\hline
\end{tabular}




\begin{tabular}{|c|c|}
\hline Intervention details: & $\begin{array}{l}\text { Medical records of all dogs that underwent intestinal resection and } \\
\text { anastomosis using disposable staples at two separate specialty } \\
\text { referral hospitals were reviewed. }\end{array}$ \\
\hline Study design: & Retrospective study. \\
\hline Outcome studied: & $\begin{array}{l}\text { Mortality associated with certain variables in dogs } \\
\text { undergoing intestinal resection and anastomosis performed } \\
\text { with the use of disposable skin staples. } \\
\text { Variables evaluated; sex, body weight, breed, duration of } \\
\text { hospital stay, indication for surgery, location of resection } \\
\text { and anastomosis, number of surgical procedures performed, } \\
\text { evidence of presence of peritonitis at the time of surgery, } \\
\text { whether surgeon was residency trained, dehiscence, } \\
\text { mortality. } \\
\text { Mortality was defined as those who died or were euthanised } \\
\text { within a } 10 \text { day follow-up period. }\end{array}$ \\
\hline $\begin{array}{l}\text { Main findings: } \\
\text { (relevant to PICO question): }\end{array}$ & $\begin{array}{l}\text { Of the dogs whose indication for surgery was a diagnosis of foreign } \\
\text { body, } 18 / 19 \text { survived and one dog died. }\end{array}$ \\
\hline Limitations: & Retrospective study. \\
\hline
\end{tabular}

\begin{tabular}{|c|c|}
\hline Ichik et al. (2019) & \\
\hline Population: & $\begin{array}{l}\text { Client-owned dogs with intestinal foreign bodies treated with } \\
\text { enterotomy between November 2001-September } 2017 \text {. }\end{array}$ \\
\hline Sample size: & 247 dogs. \\
\hline Intervention details: & $\begin{array}{l}\text { Medical records were searched for dogs that underwent enterotomy } \\
\text { for removal of intestinal foreign bodies from November 2001- } \\
\text { September } 2017 \text { at veterinary institution 1, and from June 2005- } \\
\text { September } 2017 \text { at veterinary institution 2. }\end{array}$ \\
\hline Study design: & Retrospective study. \\
\hline Outcome studied: & $\begin{array}{l}\text { Preoperative data evaluated for risk of dehiscence: } \\
\text { signalment, body weight, body condition score, previous } \\
\text { gastrointestinal surgery, pervious or current NSAID or } \\
\text { corticosteroid treatment, presence of preoperative } \\
\text { peritonitis, reported comorbidities, and preoperative } \\
\text { bloodwork when available. } \\
\text { - Intraoperative data evaluated for risk of dehiscence: date } \\
\text { and duration of procedure, whether surgery was performed } \\
\text { after hours, total duration of surgery and general } \\
\text { anesthesia, frequency and duration of intraoperative } \\
\text { hypotension, suture material and pattern, whether or not } \\
\text { concurrent gastrotomy was performed, type of foreign body, } \\
\text { other concurrent surgical procedures performed, any } \\
\text { abnormal findings during exploratory surgery. } \\
\text { Postoperative data evaluated for risk of dehiscence: } \\
\text { occurrence of intestinal dehiscence, survival to hospital } \\
\text { discharge, duration of hospitalization, treatment with } \\
\text { NSAIDs or corticosteroids, date of last follow-up, occurrence } \\
\text { of any surgery related complications. }\end{array}$ \\
\hline
\end{tabular}




\begin{tabular}{|c|c|}
\hline $\begin{array}{l}\text { Main findings: } \\
\text { (relevant to PICO question): }\end{array}$ & $2 / 247(0.8 \%)$ dogs did not survive to hospital discharge. \\
\hline Limitations: & Retrospective study. \\
\hline \multicolumn{2}{|l|}{ Ralphs et al. (2003) } \\
\hline Population: & $\begin{array}{l}\text { All dogs and cats that underwent intestinal resection and } \\
\text { anastomosis from 1991-2000 at the University of Minnesota } \\
\text { teaching hospital. }\end{array}$ \\
\hline Sample size: & 90 and 25 cats. \\
\hline Intervention details: & $\begin{array}{l}\text { - Medical records for all dogs and cats that underwent } \\
\text { intestinal resection and anastomosis from } 1991-2000 \text { at the } \\
\text { University of Minnesota teaching hospital were reviewed. } \\
\text { Data on preoperative, intraoperative, and postoperative } \\
\text { parameters were recorded. }\end{array}$ \\
\hline Study design: & Retrospective study. \\
\hline Outcome studied: & $\begin{array}{l}\text { - Preoperative factors evaluated as risk factors for dehiscence: } \\
\text { Species, breed, age, sex, body weight, initial compliant, } \\
\text { duration of anorexia prior to surgery, steroid admission prior } \\
\text { to surgery, whether there was evidence for peritonitis prior } \\
\text { to surgery, White Blood Cell count (WBC) with or without } \\
\text { left shift, platelet count, serum albumin, indication for } \\
\text { surgery. } \\
\text { - Intraoperative factors evaluated as risk factors for } \\
\text { dehiscence: Segment of bowel resected, surgeon } \\
\text { experience, suture pattern, anesthesia and surgery time. } \\
\text { Postoperative factors evaluated as risk factors for } \\
\text { dehiscence: Duration of hospitalisation, whether patient ate } \\
\text { the day after surgery, whether supplemental alimentation } \\
\text { was provided, blood products administered, patient death } \\
\text { as result of perioperative complications, confirmation of } \\
\text { intestinal anastomotic leakage and how long leakage } \\
\text { occurred after surgery if applicable. }\end{array}$ \\
\hline $\begin{array}{l}\text { Main findings: } \\
\text { (relevant to PICO question): }\end{array}$ & $\begin{array}{l}\text { - } 38 / 90(40 \%) \text { underwent intestinal resection and anastomosis } \\
\text { surgery because of a foreign body. } \\
\text { - Anastomotic leakage occurred in } 10 / 38(26 \%) \text { dogs that } \\
\text { underwent intestinal resection and anastomosis due to a } \\
\text { foreign body and } 3 / 52(6 \%) \text { of dogs with resection and } \\
\text { anastomosis for other reasons. } \\
\text { - Development of anastomotic leakage significantly impacted } \\
\text { outcome. } 11 / 13(85 \%) \text { of the leakage group died, compared } \\
\text { to } 8 / 77(10 \%) \text { mortality in the non-leakage group. }\end{array}$ \\
\hline Limitations: & Retrospective study. \\
\hline
\end{tabular}

\section{Appraisal, application and reflection}

It has been presumed that resection and anastomosis procedures are associated with a higher mortality rate than enterotomy, which is regarded as a simpler procedure. Time of obstruction prior to surgery is a possible factor that contributes to the damage done by obstruction and therefore the decision of which procedure is 
indicated. When discussing options with clients regarding intestinal foreign-body treatment, it is important to be able to communicate risks when offering treatment options.

Habenbacher et al. (2019) found that resection and anastomosis was associated with a higher probability of death than enterotomy when removing foreign bodies. Rosenbaum et al. (2016) found that of the dogs whose indication for surgery was foreign-body obstruction, $1 / 19$ died. Strelchick et al. (2019) found that $2 / 247$ (0.8\%) of dogs with foreign bodies undergoing enterotomies died. Ralphs et al. (2003) found that $10 / 38(26 \%)$ of the dogs that underwent resection and anastomosis procedures for foreign bodies had an anastomotic leakage which was significantly higher than any other cause for intestinal surgery, and that anastomotic leakage significantly impacts outcome. Based on these papers that are all retrospective, and only one with a direct comparison of enterotomy and resection and anastomosis, there is weak evidence that resection and anastomosis has a higher probability of death, but actual death rates cannot be compared.

This search did not produce many papers that specifically and directly report mortality as an outcome, as well as clearly separating foreign-body obstruction as a cause for surgery, and make a clear distinction of which populations within their sample size received a resection and anastomosis versus an enterotomy. These specifics significantly narrowed the scope of studies included within the very specific PICO question. However, the authors acknowledge that there are factors impacting mortality that are not within the scope of this PICO question.

Dehiscence was identified as a risk factor for mortality. Snowden et al. (2016) found that of dogs receiving a stapled functional end-to-end anastomosis, there was an overall mortality rate of 5/6 (83\%), compared to a mortality rate of $10 / 47(21 \%)$ for those who did not have dehiscence. This study, however, did not differentiate between dogs whose indication for surgery was foreign-body obstruction versus other causes, and so was excluded. Duell et al. (2016) found that of dogs that experienced intestinal dehiscence, 22/29 (76\%) did not survive a two-week postoperative period, compared to $3 / 17(62 \%)$ in those whom did not experience post-operative dehiscence.

There are other risk factors in addition to surgical procedure that have an impact on survival. Gill et al. (2019) do not differentiate those which had a resection and anastomosis from those who received an enterotomy when reporting mortality rate, and so their paper was excluded. What they do report, however, was that preoperative and intraoperative bacterial peritonitis was more common among those dogs receiving a resection and anastomosis $(18 / 81 ; 22 \%)$. Bacterial peritonitis, in turn, was associated with a higher mean American Society of Anesthesiologists (ASA) status $(2.9, \pm 1)$, versus those who were not found to have preoperative or intraoperative septic peritonitis $(2.3, \pm 1)$. This study also found that those that did not survive the two-week period following surgery had a higher ASA status than those who survived. This study also found that dogs with postoperative dehiscence were more likely to have had a resection and anastomosis than other types of surgery, though no specific statistic is reported. Grimes et al. (2011) also found that preoperative septic peritonitis had a significant correlation with failure to survive following surgery.

Similarly, the authors acknowledge that there are different techniques (stapling methods and hand suturing) when performing resection and anastomosis that may affect the dehiscence rate and therefore mortality rate, however the question being evaluated was specifically addressing all resection and anastomosis versus all enterotomies without specifying suture or staple methods. Duell et al. (2016) did not report mortality rates; however, it is worth noting that they did not find a higher dehiscence rate for hand-sutured anastomoses when compared to stapled anastomoses.

Presence of a linear foreign body was found to have a negative impact on survival (Hayes, 2009). Intraoperative hypotension was found to be correlated with postoperative dehiscence of the anastomotic site by Snowden et al. (2016).

Ideally, for the best evidence, a study randomizing dogs with foreign bodies to either enterotomy versus resection and anastomosis with a large enough sample size that the other risk factors would be balanced across groups would be performed. However, this type of study cannot be performed ethically as resection 
and anastomosis is sometimes necessary because of the amount of damage to the intestine and therefor the randomization could not be maintained. Alternatively, a prospective observational study including all dogs undergoing either enterotomy or resection and anastomosis (enterectomy) for a gastrointestinal foreign body could be performed. Data collected would include possible risk factors (presence of preoperative septic peritonitis, hydration status, bloodwork abnormalities, interoperative factors, post-operative factors, and comorbidities), enterotomy versus resection and anastomosis, and the mortality rates.

However, at this time, there were no studies directly comparing mortality rates between enterotomies and resection and anastomosis in dogs with gastrointestinal foreign bodies. Risk can be extrapolated from many studies, but none set out with the specific aim of comparing mortality rates. Evidence is lacking and studies aimed at this specific objective would be valuable.

\section{Methodology Section}

\begin{tabular}{|c|c|}
\hline \multicolumn{2}{|l|}{ Search Strategy } \\
\hline $\begin{array}{r}\text { Databases searched and dates } \\
\text { covered: }\end{array}$ & CAB Abstracts \& PubMed; (1910 to 2020) \\
\hline Search terms: & 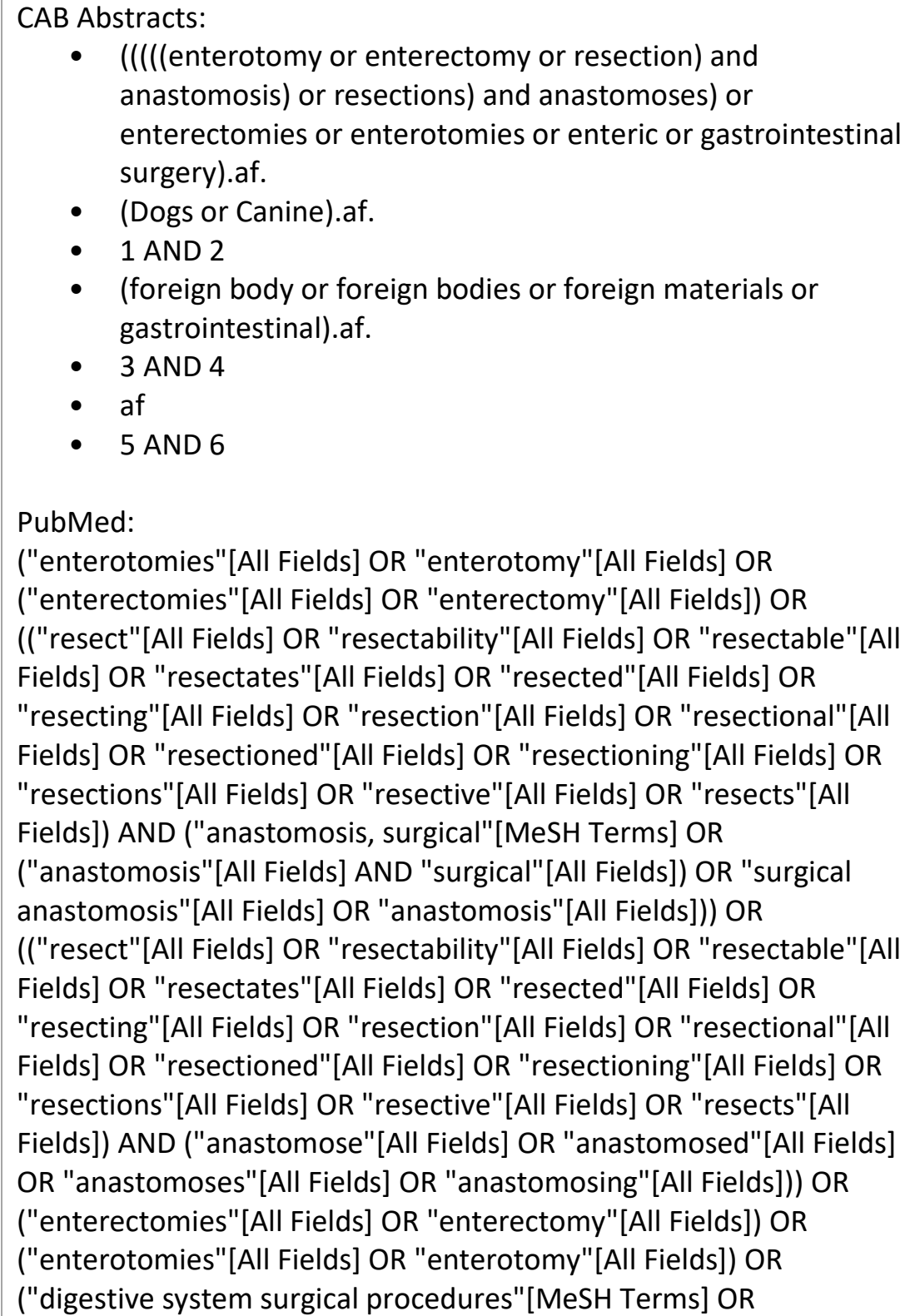 \\
\hline
\end{tabular}


("digestive"[All Fields] AND "system"[All Fields] AND "surgical"[All Fields] AND "procedures"[All Fields]) OR "digestive system surgical procedures"[All Fields] OR ("gastrointestinal"[All Fields] AND "surgery"[All Fields]) OR "gastrointestinal surgery"[All Fields]) OR (("enteric"[All Fields] OR "enterically"[All Fields] OR "enterics"[All Fields] OR "enteritis"[MeSH Terms] OR "enteritis"[All Fields] OR "enteritides"[All Fields]) AND ("surgery"[MeSH Subheading] OR "surgery"[All Fields] OR "surgical procedures, operative"[MeSH Terms] OR ("surgical"[All Fields] AND "procedures"[All Fields] AND "operative"[All Fields]) OR "operative surgical procedures"[All Fields] OR "general surgery"[MeSH Terms] OR ("general"[All Fields] AND "surgery"[All Fields]) OR "general surgery"[All Fields] OR "surgery $s "[$ [ll Fields] OR "surgerys"[All Fields] OR "surgeries"[All Fields])) OR (("intestinalization"[All Fields] OR "intestinalized"[All Fields] OR "intestinally"[All Fields] OR "intestinals"[All Fields] OR "intestine $s "[A l l$ Fields] OR "intestines"[MeSH Terms] OR "intestines"[All Fields] OR "intestinal"[All Fields] OR "intestine"[All Fields]) AND ("surgery"[MeSH Subheading] OR "surgery"[All Fields] OR "surgical procedures, operative"[MeSH Terms] OR ("surgical"[All Fields] AND "procedures"[All Fields] AND "operative"[All Fields]) OR "operative surgical procedures"[All Fields] OR "general surgery"[MeSH Terms] OR ("general"[All Fields] AND "surgery"[All Fields]) OR "general surgery"[All Fields] OR "surgery s"[All Fields] OR "surgerys"[All Fields] OR "surgeries"[All Fields]))) AND ("dogs"[MeSH Terms] OR "dogs"[All Fields] OR ("canine s"[All Fields] OR "dogs"[MeSH Terms] OR "dogs"[All Fields] OR "canine"[All Fields] OR "canines"[All Fields]) OR ("dogs"[MeSH Terms] OR "dogs"[All Fields] OR "dog"[All Fields]) OR ("canine s"[All Fields] OR "dogs"[MeSH Terms] OR "dogs"[All Fields] OR "canine"[All Fields] OR "canines"[All Fields])) AND ("foreign bodies"[MeSH Terms] OR ("foreign"[All Fields] AND "bodies"[All Fields]) OR "foreign bodies"[All Fields] OR ("foreign"[All Fields] AND "body"[All Fields]) OR "foreign body"[All Fields] OR ("foreign bodies"[MeSH Terms] OR ("foreign"[All Fields] AND "bodies"[All Fields]) OR "foreign bodies"[All Fields] OR ("foreign"[All Fields] AND "material"[All Fields]) OR "foreign material"[All Fields]) OR ("foreign bodies"[MeSH Terms] OR ("foreign"[All Fields] AND "bodies"[All Fields]) OR "foreign bodies"[All Fields])) AND (("intestinalization"[All Fields] OR "intestinalized"[All Fields] OR "intestinally"[All Fields] OR "intestinals"[All Fields] OR "intestine $s "[A l l$ Fields] OR "intestines"[MeSH Terms] OR "intestines"[All Fields] OR "intestinal"[All Fields] OR "intestine"[All Fields]) AND ("surgery"[MeSH Subheading] OR "surgery"[All Fields] OR "surgical procedures, operative"[MeSH Terms] OR ("surgical"[All Fields] AND "procedures"[All Fields] AND "operative"[All Fields]) OR "operative surgical procedures"[All Fields] OR "general surgery"[MeSH Terms] OR ("general"[All Fields] AND "surgery"[All Fields]) OR "general surgery"[All Fields] OR "surgery s"[All Fields] OR "surgerys"[All Fields] OR "surgeries"[All Fields]))

Hand Search:

Habenbacher et al. is no longer available on CAB Abstracts as of the search on 25 October 2020. As it is relevant and has not been 
retracted, the authors have elected to include it in this Knowledge

Summary.

Dates searches performed: 25 Oct 2020

\section{Exclusion / Inclusion Criteria}

Exclusion: Full articles not available, not relevant to PICO, not available in English.

Inclusion: Full-text articles available in English relevant to PICO.

\begin{tabular}{|c|c|c|c|c|c|}
\hline \multicolumn{6}{|c|}{ Search Outcome } \\
\hline Database & $\begin{array}{l}\text { Number } \\
\text { of results }\end{array}$ & $\begin{array}{l}\text { Excluded - } \\
\text { Irrelevant to } \\
\text { PICO }\end{array}$ & $\begin{array}{l}\text { Excluded - Full-text } \\
\text { article not available }\end{array}$ & $\begin{array}{c}\text { Excluded - Not } \\
\text { available in English }\end{array}$ & $\begin{array}{l}\text { Total } \\
\text { relevant } \\
\text { papers }\end{array}$ \\
\hline CAB Abstracts & 17 & 17 & 0 & 0 & 0 \\
\hline PubMed & 97 & 94 & 0 & 0 & 3 \\
\hline Hand Search & 1 & 0 & 0 & 0 & 1 \\
\hline \multicolumn{5}{|c|}{ Total relevant papers when duplicates removed } & 4 \\
\hline
\end{tabular}

\section{CONFLICT OF INTEREST}

The authors declare no conflict of interest.

\section{REFERENCES}

1. Duell, J.R., Thieman Mankin, K.M., Rochat, M.C., Regier, P.J., Singh, A., Luther, J.K., Mison, M.B., Leeman, J.J. \& Budke, C.M. (2016). Frequency of dehiscence in hand-sutured and stapled intestinal anastomoses in dogs. Veterinary Surgery. 45(1), 100-103. DOI: https://doi.org/10.1111/vsu.12428

2. Gill, S.S., Buote, N.J., Peterson, N.W. \& Bergman, P.J. (2019). Factors associated with dehiscence and mortality rates following gastrointestinal surgery in dogs. Journal of the American Veterinary Medical Association. 255(5), 569-573. DOI: https://doi.org/10.2460/javma.255.5.569

3. Grimes, J.A., Schmiedt, C.W., Cornell, K.K. \& Radlinksy, M.A.G. (2011). Identification of risk factors for septic peritonitis and failure to survive following gastrointestinal surgery in dogs. Journal of the American Veterinary Medical Association. 238(4), 486-494.

DOI: https://doi.org/10.2460/javma.238.4.486

4. Habenbacher, B., Bockstahler, B., Tichy, A. \& Dupre, G. (2019). Enterotomy versus intestinal resection anastomosis: morbidity and mortality rates in 135 dogs and 85 cats. Wiener Tierarztliche 
Monatsschrift. 106(5/6), 117-127. [onine] Available

from: http://ovidsp.ovid.com/ovidweb.cgi?T=JS\&PAGE=reference\&D=caba6\&NEWS=N\&AN=20193423 203 [Accessed 8 Jul 2020]

5. Hayes, G. (2009). Gastrointestinal foreign bodies in dogs and cats: a retrospective study of 208 cases. Journal of Small Animal Practice. 50(11), 576-583. DOI: https://doi.org/10.1111/j.17485827.2009.00783.x

6. Ralphs, S.C., Jessen, C.R. \& Lipowitz, A.J. (2003). Risk factors for leakage following intestinal anastomosis in dogs and cats: 115 cases (1991-2000). Journal of the American Veterinary Medical Association. 223(1), 73-77. DOI: https://doi.org/10.2460/javma.2003.223.73

7. Rosenbaum, J.M., Coolman, B.R., Davidson, B.L., Daly, M.L., Rexing, J.F. \& Eatroff, A.E. (2016). The use of disposable skin staples for intestinal resection and anastomosis in 63 dogs: 2000 to 2014. The Journal of Small Animal Practice. 57(11), 631-636. DOI: https://doi.org/10.1111/isap.12584

8. Snowdon,A., Smeak, D.D. \& Chiang, S. (2015). Risk factors for dehiscence of stapled functional end-toend intestinal anastomoses in dogs: 53 cases (2001-2012). Veterinary Surgery. 45(1), 91-99.

DOI: https://doi.org/10.1111/vsu.12413

9. Strelchik, A., Coleman, M.C., Scharf, V.F., Stoneburner, R.M. \& Thieman Mankin, K.M. (2019). Intestinal incisional dehiscence rate following enterotomy for foreign body removal in $247 \mathrm{dogs}$. Journal of the American Veterinary Medical Association. 255(6), 695-699.

DOI: https://doi.org/10.2460/javma.255.6.695 


\section{EVIIDEFeE

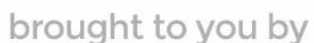 \\ RCVS KNOWLEDGE}

\section{Intellectual Property Rights}

Authors of Knowledge Summaries submitted to RCVS Knowledge for publication will retain copyright in their work, and will be required to grant RCVS Knowledge a non-exclusive license of the rights of copyright in the materials including but not limited to the right to publish, re-

publish, transmit, sell, distribute and otherwise use the materials in all languages and all media throughout the world, and to license or permit others to do so.

\section{Disclaimer}

Knowledge Summaries are a peer-reviewed article type which aims to answer a clinical question based on the best available current evidence. It does not override the responsibility

of the practitioner. Informed decisions should be made by considering such factors as individual clinical expertise and judgement along with patient's circumstances and owners' values. Knowledge Summaries are a resource to help inform and any opinions expressed within the Knowledge Summaries are the author's own and do not necessarily reflect the view of the RCVS Knowledge. Authors are responsible for the accuracy of the content. While the

Editor and Publisher believe that all content herein are in accord with current recommendations and practice at the time of publication, they accept no legal responsibility

for any errors or omissions, and make no warranty, express or implied, with respect to material contained within.

For further information please refer to our Terms of Use.

RCVS Knowledge is the independent charity associated with the Royal College of Veterinary Surgeons (RCVS). Our ambition is to become a global intermediary for evidence based veterinary knowledge by providing access to information

that is of immediate value to practicing veterinary professionals and directly contributes to evidence based clinical decision-making.

https://www.veterinaryevidence.org/

RCVS Knowledge is a registered Charity No. 230886.

Registered as a Company limited by guarantee in England and Wales No. 598443.

Registered Office: Belgravia House, 62-64 Horseferry Road, London SW1P 2AF

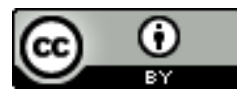

This work is licensed under a Creative Commons Attribution 4.0 International License 